\title{
Successful endoscopic ultrasound-assisted resection of a giant ulcerated rectal lipoma causing hematochezia
}

Most colonic lipomas occur in the cecum and ascending colon, are asymptomatic, and need no treatment. However, lesions exceeding $2 \mathrm{~cm}$ in diameter may produce symptoms [1,2]. We report successful endoscopic ultrasound (EUS)-assisted resection of a large ulcerated rectal lipoma presenting hematochezia.

A 53-year-old woman presented with a 3month history of intermittent hematochezia. Colonoscopic examination revealed a soft, approximately 2-cm diameter, yellowish polypoid mass with normal surface mucosa except for a 0.9 -cm central ulceration $8 \mathrm{~cm}$ from the anal verge ( Fig. 1). With no other significant findings on colonoscopy except the ulcerated lipoma, we concluded that the lipoma was the likely cause of the hematochezia.

Endoscopic ultrasonography was performed and revealed a $2.0 \times 1.6-\mathrm{cm}$ homogeneous, hyperechoic, round mass lesion at the submucosal layer ( Fig. 2). Based on these findings, we diagnosed this tumor as a 'giant' lipoma and concluded that this submucosal tumor could be resected endoscopically. Saline solution was injected into the base of the lesion, which was then removed via monopolar electrosurgical snare resection ( Fig. 3 ). Histological examination revealed a characteristic colonic lipoma with ulceration. Many reports have suggested that endoscopic treatment of large symptomatic lipomas is a valid alternative to surgery. However, the decision to remove lipomas and the best technique for doing so, either endoscopically or surgically, remains controversial because high risks of hemorrhage and perforation associated with the removal of large lipomas have been documented [3]. Colonic lipomas arise in the submucosa but occasionally extend into the muscularis propria or subserosa. EUS can be used to determine whether a lipoma extends into the muscularis propria, which is a risk factor for perforation that should preclude endoscopic removal. With improvements in EUS and injection-assisted polypectomy techniques, endoscopic treatment can successfully achieve complete resection of giant lipomas with fewer complications [4].
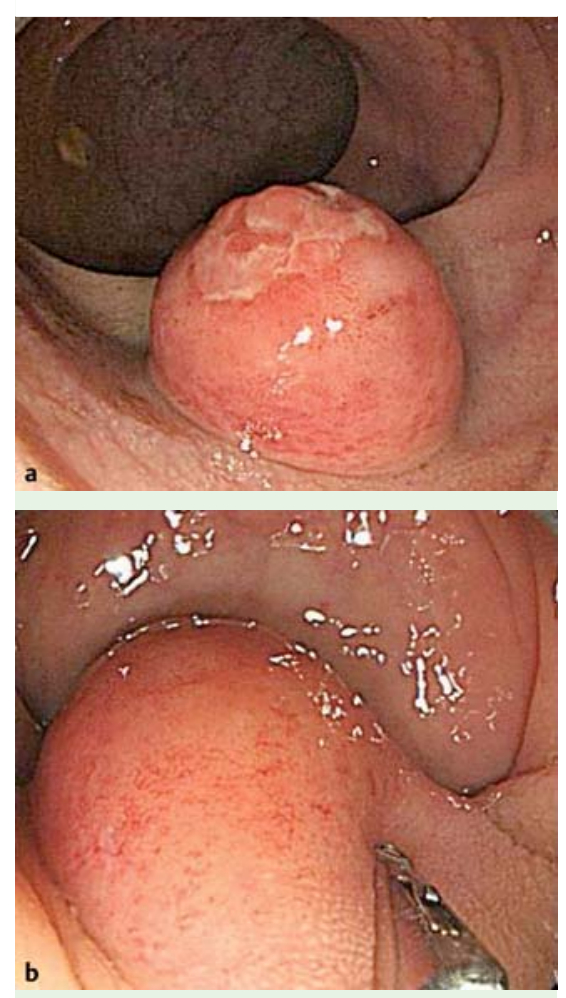

Fig. 1 Endoscopic images of the polypoid mass showing: a normal surface mucosa except for a $0.9-\mathrm{cm}$ central ulceration; b cushion sign.

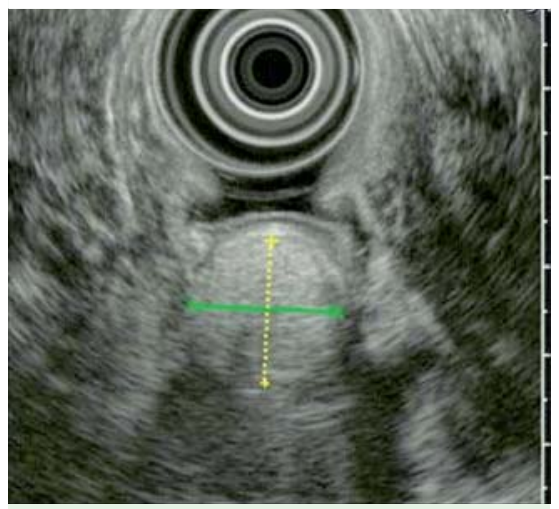

Fig. 2 Endoscopic ultrasound (EUS) image of lipoma, demonstrating the hyperechoic submucosal feature.
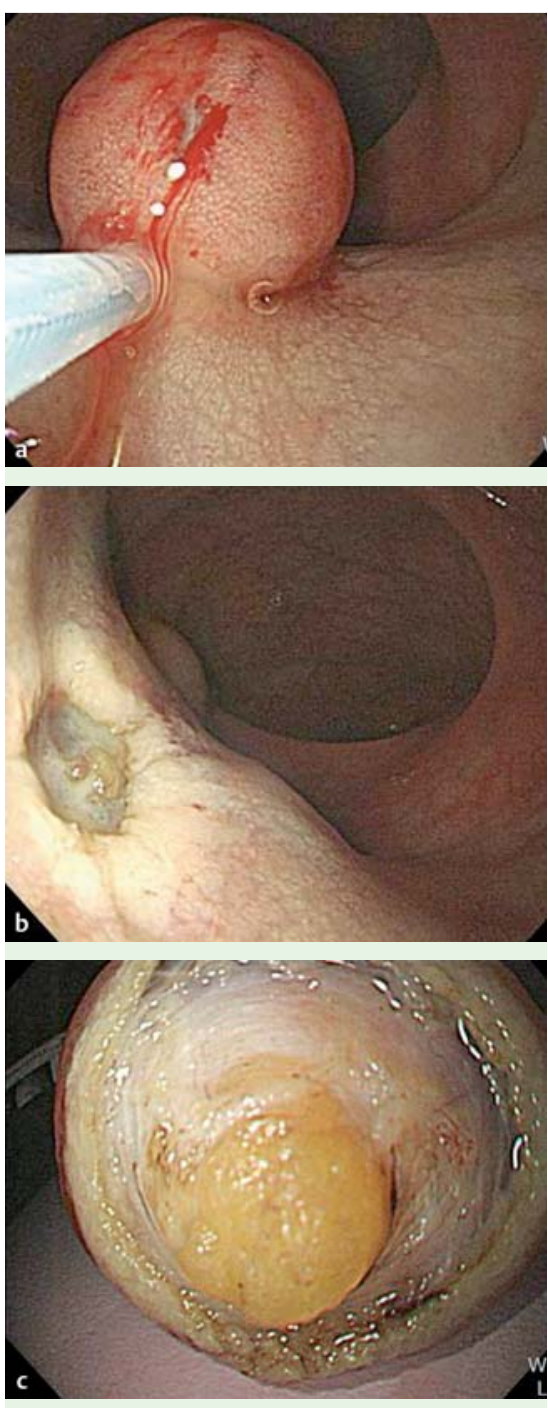

Fig. 3 a Injection of saline solution into the base of the lesion, and snare polypectomy. b Result of polypectomy. c The removed lesion, demonstrating the 'naked fat sign'. 
Endoscopy_UCTN_Code_CCL_1AD_2AC

Competing interests: None

C.-S. Lim, S.-J. Park, M.-I. Park, W. Moon, H.-H. Kim, B.-J. Kim, D.-Y. Ku, J.-H. Yoo, S.-H. Jeong, S.-E. Kim, J.-H. Paek Division of Gastroenterology, Department of Internal Medicine, Kosin University Gospel Hospital

\section{References}

1 El-Khalil T, Mourad FH, Uthman S. Sigmoid lipoma mimicking carcinoma: case report with review of diagnosis and management. Gastrointest Endosc 2000; 51: 495-596

2 Meghoo CA, Cook PR, McDonough CA et al. Large colonic lipoma with mucosal ulceration mimicking carcinoma. Gastrointest Endosc 2003; 58: $468-470$

3 Pfeil SA, Weaver HG, Abdulkarim F, Yang P. Colonic lipomas: outcome of endoscopic removal. Gastroinest Endosc 1990; 36: 435 438

$4 \mathrm{Kim}$ CY, Bandres D, Tio TL et al. Endoscopic removal of large colonic lipomas. Gastrointest Endosc 2002; 55: 929-931
Bibliography

DOI $10.1055 / \mathrm{s}-0030-1256948$

Endoscopy 2012; 44: E306-E307

(c) Georg Thieme Verlag KG Stuttgart · New York . ISSN 0013-726X

Corresponding author

\section{S.-J. Park, MD}

Division of Gastroenterology

Department of Internal Medicine

Kosin University Gospel Hospital

34 Amnam-dong

Seo-gu

Busan 602-702

Korea

Fax: +82-51-990-3005

parksj6406@yahoo.co.kr 